\title{
'Capacity' and the Adults with Incapacity (Scotland) Act 2000
}

\author{
D Winskill \\ Associate, Gillespie Macandrew LLP, Edinburgh, UK
}

KEYWORDS assessment, capacity, guardianship, incapacity, legal authority, power of attorney

DECLARATION OF INTERESTS No conflict of interests declared.

\author{
Correspondence to D Winskill \\ Gillespie Macandrew LLP \\ 5 Atholl Crescent \\ Edinburgh EH3 8EJ \\ UK
}

e-mail donald.winskill@

gillespiemacandrew.co.uk

\section{INTRODUCTION}

When actions need to be taken, or decisions require to be made, on behalf of adults unable to manage their own affairs (i.e. individuals over the age of 16), the Adults with Incapacity (Scotland) Act 2000 (the 2000 Act) provides these options: continuing and welfare Powers of Attorney; access to funds and use of joint accounts; management of residents' funds; authorising medical treatment and research; intervention orders/guardianship orders in respect of property, finances, and personal welfare.

Before using any of the above, check carefully whether the person can be helped to make and communicate a valid decision, or may regain sufficient capacity to do so before the need for a decision becomes urgent.

In order to ascertain and achieve the most appropriate solution in any given set of circumstances, you may be responsible for carrying out a formal assessment to determine whether or not the individual suffers from 'incapacity' in terms of the 2000 Act. Having a working knowledge of these options, as well as an understanding of what the law means by 'capacity' or 'incapacity' in these situations, should make your task easier.

Solicitors also fall within the category of persons authorised to certify that an individual is able to comprehend the nature and effect of a Power of Attorney (POA). Most solicitors will seek an independent medical assessment only in cases of doubt; others, however, will ask doctors to sign the certificate of capacity as a matter of course.

\section{CAPACITY OR INCAPACITY: WHAT ARE YOU BEING ASKED TO CERTIFY?}

This will depend on which measure under the 2000 Act is being contemplated.

\section{Continuing and Welfare Power of Attorney}

This is a document where an individual (with present capacity) can give someone they trust the authority to make financial or welfare decisions on their behalf if they lose capacity in the future.

You may be asked to sign a certificate confirming that, among other things:

- the individual understands the nature and extent of the POA at the time it is granted

- the individual understands the effect of a document that revokes a POA granted previously

- there is no undue influence and no other vitiating factors; it is important to take legal advice if you are unsure about these concepts

\section{Access to funds}

For situations where an individual does not have the capacity to manage their day-to-day finances, the Public Guardian can authorise someone to uplift money from a bank or building society account held in the individual's sole name, and use it to settle their bills and other living expenses.

\section{Management of residents' funds}

If an individual living in a hospital or care home lacks capacity to manage their financial affairs and has no Department of Work and Pensions appointee, attorney, or guardian with relevant powers, the Care Inspectorate or relevant Health Board can authorise the manager of the accommodation to take control of the resident's finances and moveable property (up to specified limits and subject to certain safeguards).

\section{Medical treatment and research}

Where an individual is incapable of making a decision regarding a proposed treatment or procedure designed to safeguard or promote their physical or mental health, the doctor (or other professional who meets specified 
criteria), who is primarily responsible for the individual's medical treatment, may authorise it.

\section{Intervention order/guardianship order}

If an individual is incapable of taking action or making a decision about their property, financial affairs, or personal welfare, and none of the mechanisms listed above would lead to the desired outcome, the Sheriff Court can grant an order authorising someone else to take the necessary steps on the individual's behalf. If all that is required is a one-off action, with a clear end result, it is likely that an Intervention Order would suffice, in which case the appointed person's authority would come to an end when that result had been achieved. If, however, the individual's welfare and/or finances need to be safeguarded on an ongoing basis, a Guardianship Order would be more suitable. The guardian's authority would be restricted to the powers specified in the order, and their appointment would last either for a fixed initial period or for the rest of the incapable individual's life. These applications usually take several months to complete and can be expensive due to their complexity. Legal Aid funding is generally available without means testing if welfare powers are required. If, on the other hand, only financial and/or property powers are needed, the incapable individual's own resources would be means-tested, so the application may have to be privately funded.

\section{Capacity is not 'all or nothing'}

In order to be valid, different types of decision-making require different levels of insight, so an individual can be perfectly capable of making certain decisions, yet lack the necessary understanding to make others. Similarly, a person's ability to comprehend a particular set of issues may vary dramatically over a given time period. Just because capacity is absent now does not necessarily mean this will still be the case in a few hours, days or weeks.

There is, however, a presumption under Scottish law that an adult has capacity unless there is evidence to the contrary. Whether or not an individual has sufficient capacity to carry out any particular action, e.g. commit to a binding contract, or give informed consent to medical treatment, is a question of law to be determined in cases of dispute by a court. It will be for the party arguing that an individual lacks capacity to prove to the court that this is the case. In reaching its conclusion, the most persuasive evidence available to the court is likely to be medical. The presumption of capacity does not apply to certification of continuing and/or welfare powers of attorney: a positive assertion of capacity is required.

The 2000 Act does not even attempt the impossible task of setting out exhaustive criteria that would satisfy the test of capacity in every given situation. Instead, it defines 'incapacity' as being unable to act, make decisions, communicate decisions, understand decisions or retain the memory of decisions due to a mental disorder or an inability to communicate by any means.

It is important to stress that this definition is exclusively for the purposes of the 2000 Act itself, including the anticipatory and responsive measures listed above. It does not provide a means of identifying whether or not an individual has sufficient capacity for other, non-2000 Act purposes, such as making a will or getting married.

\section{THE ASSESSMENT}

There are no set rules for assessing capacity, but the following are examples of questions that may help you to form an opinion.

- Does the individual realise that they have been asked to make a decision and why?

- Does the individual appreciate that they have different options, or that they may decline to make any decision?

- Does the individual understand what may happen if no decision is made?

- Is the individual aware of the background circumstances and the relevance they may have to the decision at hand?

- Can the individual weigh up the risks and benefits of each option and foresee the likely consequences of making one decision rather than another?

- Is the individual able to remember the relevant issues long enough to be able to reach an informed decision?

- Is the individual able to retain the memory of their decision for a time that is appropriate to that particular decision?

- Is the individual able to implement the decision after making it?

- Does the individual keep consistently to the same decision, and act consistently with it?

There is no standard minimum period of memory retention to indicate capacity, so you should simply judge whether the individual has remembered sufficient information for long enough in order to make a valid decision about the specific matter in question. Reaching the same decision consistently may indicate that the individual has the capacity to understand it, even if they cannot recall having been asked to consider it previously. It may, therefore, be necessary to assess the individual on more than one occasion.

Your assessment should be carried out in a manner that will help the individual as much as possible to understand and participate in the process, and demonstrate decision-making capacity.Among other things, this may involve the following.

- Choosing a time when the individual is comfortable and alert 
- Choosing a quiet and familiar venue in which the individual is at ease

- Speaking clearly, slowly, and in short, simple terms, avoiding medical or legal jargon (without being patronising)

- Use any other method of communication if necessary: note that you have an absolute obligation to let the individual communicate if that is possible by any means whatsoever

- Being patient and giving the individual plenty of time to consider and respond

- Showing the individual respect and avoiding assumptions about their abilities

- Addressing one issue at a time, rather than confusing the individual with too much information at once

- Checking whether one issue has been understood before moving on to the next

- If the individual hasn't understood something you have said, phrasing it differently (rather than simply repeating yourself)

- Using sign language or visual aids to assist with hearing difficulties.

- Encouraging the use of hand signals, props, or body language if the individual is struggling to communicate verbally

- If you consider it likely that the individual's capacity may improve (e.g. following increased or decreased medication), allowing an opportunity for this to happen

- Accepting that it may be prudent to carry out a further assessment under different conditions if this one proves to be unsuccessful

- Beware of possible undue influence, which can occur even although not visibly present

The 2000 Act states that you must not conclude that an individual lacks capacity simply because they appear to be unable to communicate their decision. All possible steps should be taken to assist them in making their views known. It may be beneficial to enlist the help of friends, relatives, or carers who have experience of overcoming the individual's particular communication difficulties, in which case you should satisfy yourself that the 'interpreted' views are genuinely those of the individual, rather than those of the interpreter. Alternatively, consider making use of independent advocacy services or consult with other professionals who have appropriate skills, e.g. speech and language therapist, specialist social worker, or clinical neuropsychologist.

You should not assume that a person lacks capacity simply because they have been diagnosed as suffering from a condition that commonly impairs capacity, e.g. Alzheimer's disease. Nor should making an unwise or eccentric decision be viewed as incapacity, although further investigation may be merited if it puts the individual at risk of harm or is clearly out of character and goes against known past wishes and actions.

With POAs in particular, be alert to the possibility of undue influence, especially if it appears the individual has been put under any pressure to sign such a document, or that the process was initiated by someone other than the individual himself. It is important to bear in mind, however, that influence may be powerful, without necessarily being undue. For example, an individual may have been strongly urged by a relative to put a POA in place. If the relative was simply trying to ensure that the individual could be looked after in the event of loss of capacity, and was not trying to persuade the individual regarding whom to appoint as attorneys, then this probably would not amount to undue influence.

Remember also that an individual's capacity may have altered significantly between the time of instructing a solicitor to prepare a POA and the time of signing it. Although solicitors should satisfy themselves that their client has capacity to understand the nature and effect of a POA before accepting instructions to draft the document, it is the individual's ability to understand the nature and effect of the document at the time of signing that is crucial. You cannot simply rely on the legal presumption of capacity, but must satisfy yourself that it exists. If you believe that the individual is unable to comprehend the document because it is full of legal jargon, consider suggesting to the instructing solicitor that a deed in simpler language be prepared.

Whatever the outcome of your assessment of an individual's capacity, you should always keep careful notes to which you can refer if you are ever asked to justify your conclusion.

It is essential to remember that an attorney has no authority to exercise any welfare powers granted under a POA unless i) the document has been registered by the Office of the Public Guardian, and ii) the granter has actually lost capacity to make the decision in question. Always ask to see the formal certificate of registration, in order to satisfy yourself that the POA has been duly registered, and that the person seeking to rely on it does actually have relevant welfare powers. It is possible that a relative who claims, and genuinely believes, that they have authority to make medical decisions has, in fact, only been given powers relating to financial and property matters. 


\section{Further reading}

For guidance and examples of what may constitute undue influence, see:

- Law Society of Scotland. Division H: Guidance on Continuing and Welfare Powers of Attorney. http://www.lawscot.org.uk/rules-andguidance/section-f-guidance-relating-to-particular-types-of-work/ division-h-guidance-on-continuing-and-welfare-powers-ofattorney/guidance/guidance-on-continuing-and-welfare-powersof-attorney/

- Law Society of Scotland. Guidance related to Rule BI.5:Vulnerable Clients Guidance. http://www.lawscot.org.uk/rules-and-guidance/ section-b/rule-bl-standards-of-conduct/guidance/b I 5vulnerable-clients-guidance

\section{A Mental Welfare Commission report on an} investigation into how a couple with mild learning disability were let down badly by the system (including doctors and solicitors, who failed to recognise undue influence) can be found here:

- Mental Welfare Commission for Scotland. Powers of attorney and their safeguards. 2012. http://www.mwcscot.org.uk/media/56140/ powers_of_attorney_and_their_safeguards.pdf

\section{Further general guidance on assessment of} capacity is available online:

- General Medical Council. Consent guidance: Part 3: Capacity issues. 2008. http://www.gmc-uk.org/guidance/ethical_guidance/ consent_guidance_part3_capacity_issues.asp

- General Medical Council. Consent guidance: patients and doctors making decisions together. 2008. http://www.gmc-uk.org/guidance/ ethical_guidance/consent_guidance_index.asp

- Scottish Government. Communication and Assessing Capacity: A guide for social work and health care staff. Edinburgh: Scottish Government; 2008. http://www.scotland.gov.uk/Resource/ Doc/210958/0055759.pdf

- Medical and Dental Defence Union of Scotland. Who decides? Glasgow: MDDUS; 2011. http://www.mddus.com/mddus/ resource-library/20 I I/gpst03/who-decides.aspx 


\section{SELF-ASSESSMENT QUESTIONS}

\section{Consent MCQs}

I. You are about to seek consent from a patient for a surgical procedure and it is unclear whether their understanding of English is sufficient to enable them to fully understand the form and the risks identified on the form.

Which ONE of the following is the CORRECT procedure?

A. Ignore the consent form.

B. Cancel the operation.

C.Ask a senior colleague to witness the form.

D. Proceed and ask them to sign anyway.

E. Seek assistance from an interpreter to explain the form prior to signature.

2. A spinal surgical procedure you are about to carry out has a risk of serious complications estimated at $\mathrm{I}-2 \%$.

Which ONE of the following is the CORRECT approach?

A. Ensure the consent form has the risks clearly outlined and obtain written consent having explained the risks.

B. Explain the risks but emphasise the small percentage risk and obtain oral consent.

C. Ignore the risks as mentioning them will just cause anxiety to the patient.

\section{Capacity MCQs}

I. What standard of proof applies to the question of capacity?
A. Balance of probabilities.
B. Beyond reasonable doubt.

2. Which measure under the Adults with Incapacity (Scotland) Act 2000 allows both doctors and solicitors to certify whether a person has capacity?
A. Intervention Order.
B. Access to funds.
C. Management of Residents' Funds.
D. Guardianship Order.
E. Power of Attorney.

3. Which ONE of following, in itself, implies incapacity for the purposes of the Adults with Incapacity (Scotland) Act 2000?
A. Making a decision that you, the assessor, do not believe any rational person would make.
B. Diagnosis of Alzheimer's disease.
C. Inability to communicate without assistance.
D. Displaying aggressive behaviour for no apparent reason.
E. Failing to understand the different consequences of making one decision over another.

4. In cases of dispute, who has the final decision as to whether or not a person has capacity?
A. The Court.
B. The certifying solicitor.
C. The certifying doctor.
D. The Public Guardian.
E.The Mental Welfare Commission.

5. Which ONE of the following bodies is not able to authorise measures under the Adults with Incapacity (Scotland) Act 2000?
A. The Mental Welfare Commission.
B. The Public Guardian.
C. The Care Inspectorate.
D. The doctor responsible for a patient's treatment.
E. The Court.

This paper was originally published as part of the Legal Topics for Physicians module on the RCPE Online Education Portal. Specialty Modules for continuing medical education, including the answers to these questions, are available to Fellows and Members at http://learning.rcpe.ac.uk 